

(RESEARCH ARTICLE)

\title{
Assessment of post-operative pain with use of rotary and conventional root canal instruments in single and multiple visit root canal treatment
}

\author{
Sheenam Markan ${ }^{1, *}$ and Gurvanit Kaur Lehl ${ }^{2}$ \\ Department of Dentistry Government Medical College \& Hospital, Sector 32, Chandigarh, India.
}

International Journal of Science and Research Archive, 2021, 02(02), 216-224

Publication history: Received on 21 April 2021; revised on 29 May 2021; accepted on 01 June 2021

Article DOI: https://doi.org/10.30574/ijsra.2021.2.2.0077

\begin{abstract}
Aim: To compare the post-operative pain after the use of rotary and conventional root canal instruments in single and multiple visit root canal treatment

Materials and Method: 168 patients requiring Root Canal Treatment [RCT] in maxillary and mandibular $1^{\text {st }}$ molar were involved in the study. On the basis of vitality and radiographic features two groups were made, multiple visit (Group A $\mathrm{n}=72$ ), single visit (Group B $\mathrm{n}=96$ ). Then the patients were randomly divided into 4 subgroups. Subgroup I $n=36$ (multiple visit conventional RCT), Subgroup II $n=36$ (multiple visit rotary RCT), Subgroup III $n=48$ (single visit Conventional RCT) and Subgroup IV n=48 (single visit rotary RCT). In subgroup I \& Subgroup III Canal preparation was done with stainless steel K files in step back manner. In subgroup II \& Subgroup IV, rotary Protaper Next was used. Irrigation was done with $3 \% \mathrm{NaOCl}$ and Ethylenediamine tetraacetic acid (EDTA) alternatively followed by obturation. The postobturation pain was recorded at $6 \mathrm{hr}, 12 \mathrm{hr}, 24 \mathrm{hr}, 1$ week using visual analogue scale. Statistical Analysis was done using Tukey HSD Post Hoc Test and ANOVA Test.
\end{abstract}

Results: Within 24 hours there was statistically significant difference between the groups $(\mathrm{p}<0.05)$ but after 7 days no statistically significant difference was there ( $p>0.05)$.

Conclusion: Patients in the groups either in single and multiple visit experience less postobturation pain if the canal preparation was done with the rotary files at all the time intervals (6hrs, $12 \mathrm{hrs}, 24 \mathrm{hrs}$ ) but after 7 days no statistical difference was found.

Keywords: Post obturation pain; Rotary instruments; Protaper Next

\section{Introduction}

One of the common treatment options for relieving odontogenic pain is root canal treatment. It is commonly associated with post-operative pain and discomfort and a cause of distress for both patient and clinician [1,2]. Various studies have reported that postobturation pain ranges from $3 \%$ to more than $50 \%[3,4]$.It is mainly affected by various factors like the vitality status of tooth [5],number of appointments, size of periapical lesion bacteriologic status [6] and type of filling material [7]. Traditionally multiple visits treatment was done but with the advancements in instruments and techniques, mainly single visit root canal treatment is preferred [8]. One visit root canal treatment is effective to both patient and doctor as it saves time [9,10]. Furthemore, it solves the other problems like intervisit leakage, loss of temporary seal, interappointment bacterial growth $[11,8]$.The chemomechanical preparation play a vital role in reducing postendodontic pain by reducing the extrusion of dentinal debris in periapical area. One of the innovations is the fifth generation ProTaper Next file systems. The file design enhances auguring debris out of a canal, results in least

\footnotetext{
${ }^{*}$ Corresponding author: Sheenam Markan

Department of Dentistry Government Medical College \& Hospital, Sector 32, Chandigarh, India.
}

Copyright (C) 2021 Author(s) retain the copyright of this article. This article is published under the terms of the Creative Commons Attribution Liscense 4.0. 
debris extrusion and thus reduce postoperative pain. In absence of in vivo studies that compare pain after root canal treatment using fifth generation file and manual files, a study was designed using VAS (Visual Analogue Scale) [12,13,14] in root canal cases done in single and multiple visit with conventional and rotary methods. The need of the study was to assess the effect of recent endodontic instruments in reducing postobturation pain in tricity patients.

\section{Methodology}

This prospective cohort study was conducted in the Department of Dentistry, Govt. Medical College and Hospital, Chandigarh from 31 October 2016 to 30 June 2017. The approval was taken from the institutional ethical committee (IEC/2017/15).

\subsection{Sample size selection based on the result of pilot study}

On the basis of pilot survey, the proportion of patients reporting with pain in multiple visit root canal treatment were found to be $20 \%$ and $60 \%$ in the two subgroups. At $5 \%$ level of significance and $90 \%$ power of the test the optimum sample size is 36 in each subgroup. Accordingly, 72 patients will be randomly divided in the subgroup I (Multiple visit root canal treatment done with conventional files) and subgroup II (Multiple visit root canal treatment done with rotary files).

On the other hand in Single visit Root canal treatment( Group B) on the basis of pilot surveying it was observed that proportion of patient reporting with pain were found to be $25 \%$ and $5 \%$. On the basis of these pilot survey results at $5 \%$ level of significance and $90 \%$ power of test optimum sample comes out to be 48 . Accordingly, 48 patients will be included in each subgroup, subgroup III - (Single visit root canal treatment done with conventional files) and subgroup IV - (Single visit root canal treatment done with rotary files).

Thus, a total of 168 patients with acute pulpitis maxillary and mandibular $1^{\text {st }}$ molar and non-vital asymptomatic maxillary and mandibular $1^{\text {st }}$ molar were enrolled in the study. Written informed consent was taken from the patients involved in the study. History, clinical examination, and radiographic investigation were done.

\subsection{Inclusion criteria}

- Patient in age group of 20-60 having odontogenic pain

- Systemically healthy patient i.e. no risk factor present that can affect oral health of the patient.

- Absence of prior hospitalization and prolonged medication during treatment.

\subsection{Exclusion criteria}

- Pregnant patients

- Patients who were on antibiotics or corticosteroids therapy at the time of treatment

- Patients having complications at the time of procedure (calcification, impossibility to achieve apical patency)

- Patients having swelling\& periapical radioluency (more than $5 \mathrm{~mm}$ )

- Immunocompromised patients

- Patients having complicating systemic disease.

- Patients below 18 years of age

- Patients not willing for the treatment.

On the basis of vitality and radiographic findings the patients were divided into single visit and multiple visit treatment. Vitality was checked with electric pulp test [EPT] and thermal test (cold test) was done. Acute cases in which bleeding was controllable, having mild to moderate pain, intentional root canal for prosthetic rehabilitation were included in single sitting and chronic cases without periapical radioluency (radioluency less than $5 \mathrm{~mm}$ ) were completed in two visits, anxious patients who didn't allow the treatment in one visit were also included in multiple visit. After that subjects were randomly divided in subgroups root canal treatment done with conventional files and root canal treatment done with rotary system. As the study was conducted in 2016 and the fifth-generation files were the invention of the time in rotary system, so in this study ProTaper Next system was used. Data was maintained for every patient including pulp vitality status, preoperative pain and degree of postobturation pain was recorded by using visual analogue scale performa at $6 \mathrm{hr}, 12 \mathrm{hr}, 24 \mathrm{hr}, 1$ week. 


\subsection{Clinical procedures}

Standard protocol for Local anaesthesia administration (Xylocaine 2\% Adrenaline 1:2,00,000), rubber dam isolation (Hygenic Dental Dam, Coltene/Whaledent Inc.) were followed. The subjects of the study were randomly divided into two subgroups. The subjects in "SubgroupI \&Subgroup III" were treated using conventional "K" files (Sybronendo files) with conventional step-back technique and "SubGroup II\& Subgroup IV" subjects were treated using rotary Protaper Next files( Maillefer, Dentsply, Switzerland). After access opening, canal patency was checked with a no. $10 \mathrm{~K}$-file [Sybronendo]. Working length was also evaluated using the same file with a Root ZX Mini apex locator [J Morita Europe, Frankfurt, Germany] and two or more angled radiographs. In teeth where the no. $10 \mathrm{~K}$ - file was loose, a no. $15 \mathrm{~K}$-file was used instead. In the subgroupsI \& III the canals were shaped via stepback technique by using conventional stainlesssteel files. In Subgroups II\& IV chemomechanical preparation was done with protaper Next files by Crown Down technique. Preparation was started with X1, followed by X2, X3, X4 and X5 were sequentially used at 300 rpm and torque of $2.6 \mathrm{~N} / \mathrm{s}$ as per manufacturer instructions with the use of X-Smart Endo-motor [Dentsply, USA]. Intermittent copious irrigation was done using $5 \mathrm{ml}, 3 \%$ sodium hypochlorite and ethylenediaminetetraacetic acid alternatively in between the instrumentation with each file. 30-gauge irrigating needle was used passively $1.5 \mathrm{~mm}$ short of its binding point and coronoapical movements were done to agitate the irrigant manually. To avoid apical debris accumulation intermittent agitation was also done using a 15-number $\mathrm{k}$ file. After completion of chemomechanical preparation, canals were flushed with $5 \mathrm{ml}$ saline and $5 \mathrm{ml}$ of $17 \%$ ethylenediaminetetraacetic acid was used as final irrigant. After this obturation was done with respective gutta percha points and AH plus sealer (Dentsply Maillefer) using lateral condensation technique.

In the Multiple visit root canal treatments were accomplished in at least two or three visits depending on the satisfactory disinfection of the canal. To eliminate any procedural discrepancy the canal preparation was performed by single operator. Drying of canal was obtained using appropriately sized absorbent paper points (Maillefer, Dentsply, Switzerland) followed by cotton pack and "Cavit G" (3M ESPE, AG, Germany) packing to ensure tight leak proof coronal seal. Permanent restoration was done with composite restoration. Patients were taught to mark on the pain rating scale (0)-none pain, (>=2)-mild pain, (>=4)-moderate pain, ( $>=6)$-strong (>=8)-severe, (>=10)-maximum. The postobturation pain was recorded at $6 \mathrm{hr}, 12 \mathrm{hr}, 24 \mathrm{hr}, 1$ week using visual analogue scale perform by the independent observer blinded to the groups. Ibuprofen $(400 \mathrm{mg})$ was prescribed for pain relief every four-six hours if the patient experienced moderate pain.

\subsection{Statistical Analysis}

Data was collected and analysed using SPSS version 24.0. Difference between groups was performed using Tukey HSD Post Hoc Test and ANOVA Test. Differences were considered significant when probabilities ( $\mathrm{p}$ value) were less than 0.05 .

\section{Results}

In subgroup I (multiple visit conventional RCT, $n=36$ ) the mean value of preoperative pain was $5.83 \pm 3.220$. After 1 week the postoperative pain score value was $0.06 \pm 0.333$ with $\mathrm{p}<.01$ (table 1 ).

Table 1 Pain analysis of Multiple visit conventional RCT at different intervals

\begin{tabular}{|l|c|c|c|c|c|}
\hline Time interval & $\mathbf{N}$ & Minimum & Maximum & Mean $^{\circledR}$ & SD \\
\hline Pre & 36 & 0 & 10 & $5.83^{\mathrm{a}}$ & 3.220 \\
\hline $6 \mathrm{hr}$ & 36 & 0 & 8 & $3.61^{\mathrm{b}}$ & 2.567 \\
\hline $12 \mathrm{hr}$ & 36 & 0 & 8 & $2.89^{\mathrm{c}}$ & 2.364 \\
\hline $24 \mathrm{hr}$ & 36 & 0 & 4 & $0.94^{\mathrm{d}}$ & 1.308 \\
\hline 1 week & 36 & 0 & 2 & $0.06^{\mathrm{e}}$ & 0.333 \\
\hline Anova test & & \multicolumn{5}{|c|}{8.11} \\
\hline p value & & $<0.01^{*}$ \\
\hline
\end{tabular}

*: statistically significant, @: Tukey HSD Post Hoc Test: Values with different letters indicate statistically significant difference as $p<0.05$ 
In subgroup II (multiple visit rotary RCT $n=36$ ) the mean value of preoperative pain score [PEP] was $6.33 \pm 3.33$ and after 1 week PEP score was $0.00 \pm 0.00$ with $\mathrm{p}<0.01$ (table 2).

Table 2 Pain analysis of multiple visit rotary RCT at different intervals

\begin{tabular}{|l|c|c|c|c|c|}
\hline Time interval & $\mathbf{N}$ & Minimum & Maximum & Mean $^{\circledR}$ & SD \\
\hline Pre & 36 & 0 & 10 & $6.33^{\mathrm{a}}$ & 3.330 \\
\hline $6 \mathrm{hr}$ & 36 & 0 & 6 & $2.28^{\mathrm{b}}$ & 1.597 \\
\hline $12 \mathrm{hr}$ & 36 & 0 & 4 & $0.89^{\mathrm{c}}$ & 1.214 \\
\hline $24 \mathrm{hr}$ & 36 & 0 & 2 & $0.06^{\mathrm{d}}$ & 0.333 \\
\hline 1 week & 36 & 0 & 0 & $0.00^{\mathrm{d}}$ & 0.000 \\
\hline Anova test & & \multicolumn{5}{|c|}{23.92} \\
\hline p value & & \multicolumn{5}{|c|}{$<0.01^{*}$} \\
\hline
\end{tabular}

*: statistically significant, ${ }^{\circledR}$ : Tukey HSD Post Hoc Test: Values with different letters indicate statistically significant difference as $\mathrm{p}<0.05$.

In subgroup III (Single visit conventional RCT, $n=48$ ) the mean value of preoperative pain was2.29 \pm 1.48 and PEP was $0.00 \pm 0.000$ after 1 week with $\mathrm{p}<0.02$ (table 3 ).

Table 3 Pain analysis of single visit conventional RCT at different intervals

\begin{tabular}{|l|c|c|c|c|c|}
\hline Time interval & $\mathbf{N}$ & Minimum & Maximum & Mean $^{\circledR}$ & SD \\
\hline Pre & 48 & 0 & 4 & $2.29^{\mathrm{a}}$ & 1.487 \\
\hline $6 \mathrm{hr}$ & 48 & 0 & 4 & $1.96^{\mathrm{a}}$ & 1.271 \\
\hline $12 \mathrm{hr}$ & 48 & 0 & 4 & $1.38^{\mathrm{b}}$ & 1.496 \\
\hline $24 \mathrm{hr}$ & 48 & 0 & 4 & $0.46^{\mathrm{c}}$ & 0.944 \\
\hline 1 week & 48 & 0 & 0 & $0.00^{\mathrm{d}}$ & 0.000 \\
\hline Anova test & & & \multicolumn{5}{|c|}{0.38} \\
\hline p value & & $0.02 *$ \\
\hline
\end{tabular}

*: statistically significant, @: Tukey HSD Post Hoc Test: Values with different letters indicate statistically significant difference as $\mathrm{p}<0.05$

In subgroup IV (Single visit rotary RCT, $\mathrm{n}=48$ ) the mean value of preoperative pain was $2.25 \pm 1.466$ and after 1 week

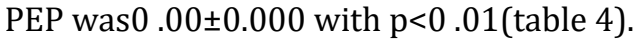

Table 4 Pain analysis of single visit rotary RCT at different intervals

\begin{tabular}{|l|c|c|c|c|c|}
\hline Time interval & $\mathbf{N}$ & Minimum & Maximum & Mean $^{@}$ & SD \\
\hline Pre & 48 & 0 & 4 & $2.25^{\mathrm{a}}$ & 1.466 \\
\hline $6 \mathrm{hr}$ & 48 & 0 & 4 & $1.17^{\mathrm{b}}$ & 1.155 \\
\hline $12 \mathrm{hr}$ & 48 & 0 & 4 & $0.71^{\mathrm{c}}$ & 1.051 \\
\hline $24 \mathrm{hr}$ & 48 & 0 & 4 & $0.13^{\mathrm{d}}$ & 0.640 \\
\hline 1 week & 48 & 0 & 0 & $0.00^{\mathrm{e}}$ & 0.000 \\
\hline Anova test & & \multicolumn{5}{|c|}{14.74} \\
\hline p value & & \multicolumn{5}{|c|}{$<0.01^{*}$} \\
\hline
\end{tabular}

*: statistically significant, ${ }^{\circledR}$ : Tukey HSD Post Hoc Test: Values with different letters indicate statistically significant difference as $\mathrm{p}<0.05$. 
The preoperative pain score in subgroups was as subgroup II (6.33) > subgroup I (5.83) > subgroup III (2.29) >subgroup IV (2.25) (table 5).

Table 5 Comparison of all techniques at different intervals

\begin{tabular}{|c|c|c|c|c|c|c|}
\hline $\begin{array}{c}\text { Time } \\
\text { interval }\end{array}$ & $\begin{array}{c}\text { Multiple visit } \\
\text { conventional RCT }\end{array}$ & $\begin{array}{l}\text { Multiple visit } \\
\text { rotary } \mathrm{RCT}\end{array}$ & $\begin{array}{c}\text { Single visit } \\
\text { conventional RCT }\end{array}$ & $\begin{array}{l}\text { Single visit } \\
\text { rotary RCT }\end{array}$ & $\begin{array}{c}\text { Anova } \\
\text { test }\end{array}$ & p value \\
\hline Pre@ & $5.83^{a}$ & $6.33^{a}$ & $2.29 \mathrm{~b}$ & $2.25^{b}$ & 10.12 & $<0.01^{*}$ \\
\hline 6 hr@ & $3.61^{a}$ & $2.28^{b}$ & $1.96^{c}$ & $1.17^{\mathrm{d}}$ & 6.14 & $0.002^{*}$ \\
\hline 12 hr@ & $2.89^{a}$ & $0.89^{b}$ & $1.38^{c}$ & $0.71^{\mathrm{b}}$ & 15.43 & $<0.01^{*}$ \\
\hline 24 hr@ & $0.94^{\mathrm{a}}$ & $0.06^{b}$ & $0.46^{c}$ & $0.13^{b}$ & 22.39 & $<0.01^{*}$ \\
\hline 1 week@ & 0.06 & 0.00 & 0.00 & 0.00 & 1.45 & 0.62 \\
\hline
\end{tabular}

*: statistically significant, ${ }^{\circledR}:$ Tukey HSD Post Hoc Test: Values with different letters indicate statistically significant difference as p $<0.05$.

After 6 hours of the completion of treatment the comparison of PEP in between subgroups was as subgroup IV $<$ subgroup III<subgroup II<subgroup I with p value 0.002.Also after12 hours the maximum pain was relieved in subgroup IV(Single visit rotary RCT) with p value <0.01(table 5).At 24 hrs. PEP comparison in between the subgroups showed was as subgroup II(Multiple visit rotary RCT) < subgroup IV(Single visit rotary RCT) < subgroup III (Single visit conventional RCT) $<$ subgroup I(Multiple visit conventional RCT) with $p$ value $<0$.01.After 7 days no significant difference was found ( $\mathrm{p}>0.05)$ (figure 1 ).

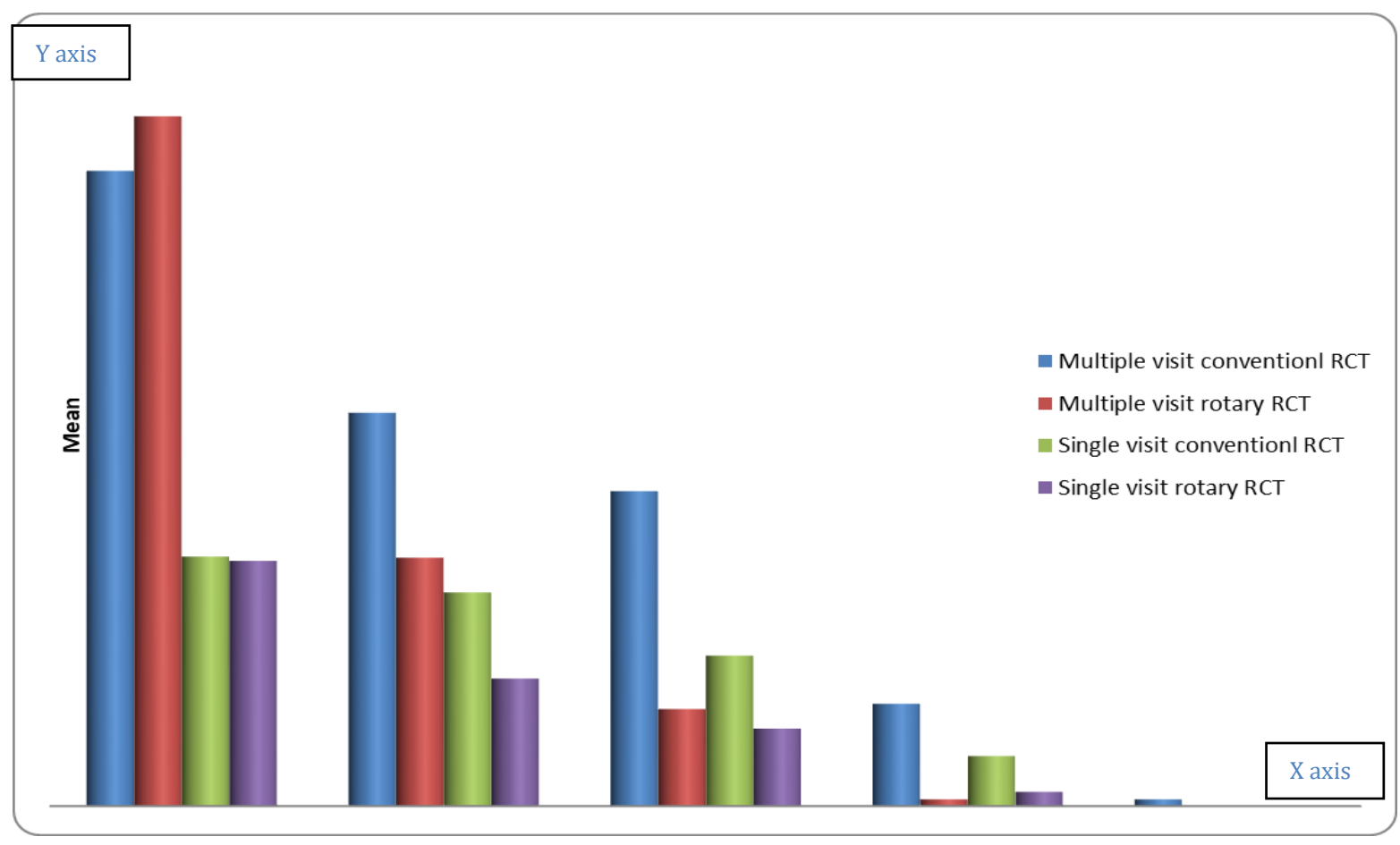

Figure 1 Comparison of all techniques at different intervals 


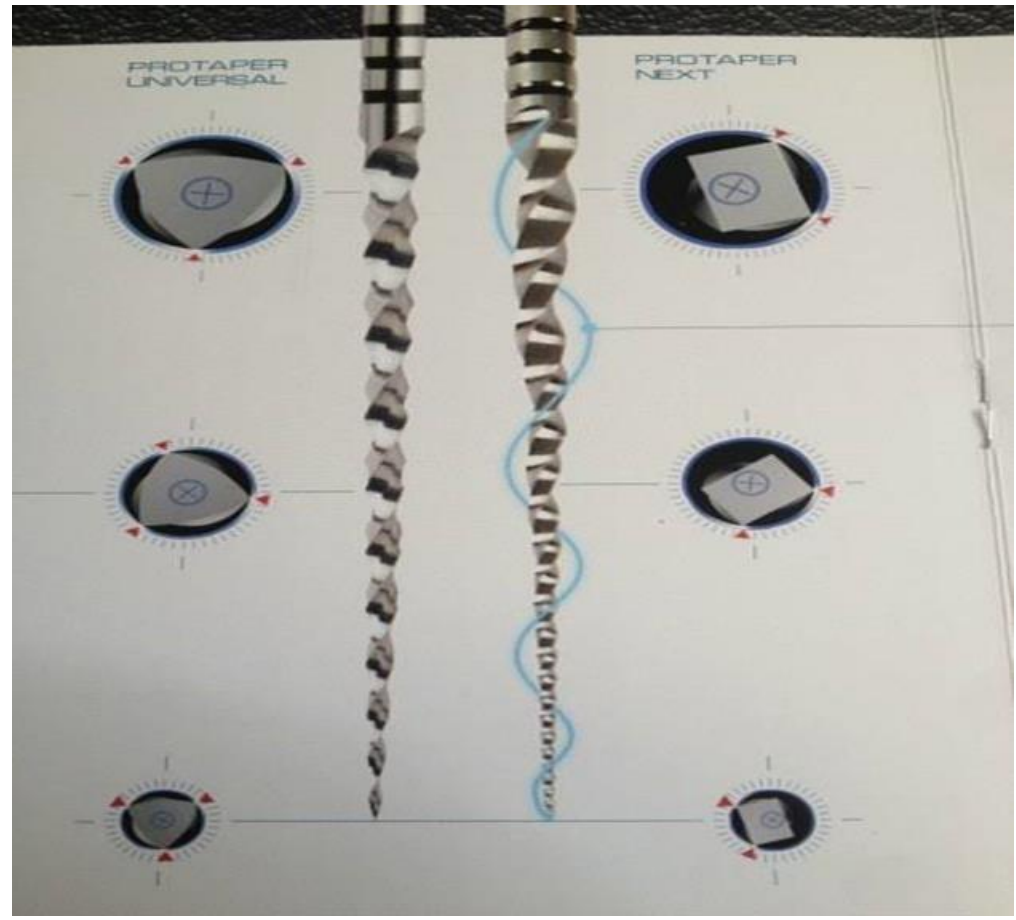

Figure 2 Dentsply Tulsa Dental specialities technique card

\section{Discussion}

The number of visits for endodontically treating the tooth is always a controversial topic. The short-term prognosis is the absence of postendodontic pain. The clinical procedures are opted not only on the basis of efficacy or biological consequences but also emphasizes on minimization of patient's discomfort. Research are focused on issues relevant to the treatments or techniques aimed to provide evidence to support clinical decisions [15]. According to various studies on the basis of vitality the single appointment procedures has widely accepted for vital cases whereas it is not universally accepted for nonvital cases [3]. On the basis of vitality and preoperative pain, like patients having delayed response in EPT and patients who required intentional root canal for prosthetic reasons were all included in the single sitting root canal, whereas those having necrotic canals without periapical radioluency, immediate pain threshold in EPT, hypermic canals, uncooperative patients all included in multiple visit root canal treatment.

As Postendodontic pain is multifactorial, one of the important factor is extrusion of debris and bacterial products during chemo mechanical preparation which is the main cause of periradicular inflammation [16]. The various advances in endodontic instruments and techniques has changed the face of endodontics. Nonethless, all the preparation techniques and instruments available till date are still associated with some degree of extrusion of debris [17]. The rotary files in crown down technique are gradually gaining increasing popularity over manual $\mathrm{k}$-files in step back technique. One of the recent advances in the plethora of rotary instruments is the fifth generation shaping files like ProTaper Next file. They are designed in such a way that the centre of mass or centre of rotation both are offset (figure 1). This design enhances removal of debris out of canal, thus resulting in least periapical extrusion and post-operative pain [18]. So in this study standard step back technique was used to compare it with the innovation in crown down technique files having variable taper.

In the absence of in vivo studies that compare postoperative pain after single and multiple root canal treatment using conventional and rotary files, a study was designed to compare the duration ,incidence and severity of postendodontic pain in single and multiple visit root canal treatment done with stainless steel files and fifth generation ProTaper Next files.

For the standardisation both maxillary and mandibular first molars were included. Other reason for this was that all the anatomical constrains are often seen in multiroooted teeth. One of the most challenging tasks for the treatment of maxillary molars is the variation in Mesiobuccal root canal morphology. A CBCT based study have detected MB2 canals in $86 \%$ maxillary first molars [19]. In this study also out of first maxillary molars requiring endodontic treatment $50 \%$ patients were having MB2 canals. 
Calcium hydroxide paste is the commonly used intracanal medicament in multiple visit root canal treatment. However, there are many controversial studies regarding its effectiveness one study showed no significant differences in posttreatment pain between the $\mathrm{Ca}(\mathrm{OH})_{2}$ groups and the dry cotton pellet groups [20] whereas another study has shown that calcium hydroxide fails to produce sterile root canals and even allows re-growth of microorganisms in some cases [21]. Moreover the studies showed that the complete removal of calcium hydroxide is impossible to achieve irrespective of the technique used .The residual calcium hydroxide will interfere with the bonding of sealer and effect the success of root canal treatment [22] .The sealer and gutta-percha are also confirmed to eliminate the residual bacteria after instrumentation [23]. Therefore, no intra-canal medicament was used in this study and same standard protocol for root canal treatment for both subgroups to achieve maximum success.

The results of this study revealed that after $6 \mathrm{hrs}$ multiple visit patients experienced more pain than the single visit patients irrespective of the techniques used in the therapy. The cause of less postobturation pain in single-visit root canal treatment might be due to immediate obturation that avoids bacterial ingress from the temporary restoration or lateral canal [24]. On the other hand, the multiple-visit technique leads to the repeated physical and chemical stimulation to periapical tissues. This is in correlation with the other studies [25]. The subgroups in which rotary preparation of the canal was done showed less post obturation pain as compared to the one done with stainless steel files. The results are in correlation with the Meta analaysis study which showed single visit root canal done with multiple rotary files experienced less pain as compared to manual and reciprocative system [26]. Similarly, Jain et al (2017) showed lesser incidence of PEP with the use of Protaper Next rotary instruments as compared to hand instruments [27]. On the contrary the Çiçek Ersan et al (2016) reported less postobturation pain by modified step back compared to reciprocating and rotary system in single sitting root canal cases [28]. The conflicting results could be related to the variation in instrument techniques and systems used to prepare the canal. Within 24hrs the multiple visit rotary subgroup showed least discomfort followed by single visit rotary subgroup. This might be due to least extrusion of dentin debris or microorganisms in periapical area.

Relatively a higher percentage of patients experienced the pain during the first 24 hours after obturation which is in accordance with the previous study [29]. The incidence and intensity of post-obturation pain in all the subgroups gradually reduced over the study period which is almost 0 in 7 days. The results are consistent with other studies findings [30] this showed that dentist should not overreact to early postobtuation symptoms by removing the obturation material.

Due to wide variation in instrumentation and obturation techniques it is often difficult to compare results from different studies, especially in studies that are more than several years old. Our findings are consistent with the previous studies published on this topic. Whether the multiple visit or single visit endodontic treatment was done, postobturation pain was less in the cases where preparation was done with rotary files. The PEP pain decreases with time which is almost 0 after 7 days in both the groups. In this study the post-operative pain was best relieved by mild analgesics, none of the patients got the swelling and required antibiotic course. Thus, the tooth pain requiring endodontic treatment is best managed by completely eliminating the source of infection as much as possible either in single or multiple visit treatment.

\section{Conclusion}

Within the limitations of the present study, the following conclusions were drawn:

- $\quad$ Patients in the groups either in single and multiple visit experience less post obturation pain if the canal preparation was done with the rotary files(Protaper Next) as compared to conventional files at all the time intervals(6hrs,12hrs,24hrs).

- Within 24 hrs the multiple visit rotary subgroup showed least discomfort followed by single visit rotary subgroup.

- Maximum pain occurs till $24 \mathrm{hrs}$ and after that the incidence and intensity of post-obturation pain in both Groups were gradually reduced over the study period.

There was no statistical difference between one-visit and two-visit root canal treatment done with rotary and conventional files on comparing the postobturation pain after 7 days. 


\section{Compliance with ethical standards}

\section{Acknowledgments}

The authors would like to thank the patients for their willingness to participate in this study.

\section{Disclosure of conflict of interest}

The manuscript has been read and approved by all the authors and the requirement of authorship as state earlier in this document have been met. Each of the authors believe that manuscript represent honest work. No conflict of interest.

\section{Statement of ethical approval}

The ethical approval was taken from the institutional ethical committee (IEC/2017/15).

\section{Statement of informed consent}

Informed consent was obtained from all individual participants included in the study.

\section{References}

[1] Siqueira JF Jr. Microbial causes of endodontic flareups.Int Endod J. 2003; 36: 453-463.

[2] Wang C, Xu P, Ren L, Dong G, Ye L. Comparison of post-obturation pain experience following one-visit and twovisit root canal treatment on teeth with vital pulps: a randomized controlled trial. Int Endod J. 2010; 43: 692-697.

[3] DiRenzo A, Gresla T, Jhonson BR, Rogers M, Tucker D, BeGole EA. Postoperative pain after 1- and2- visit root canal therapy. Oral Surg Oral Med Oral Pathol Oral Radiol Endod. 2002; 93: 605-610.

[4] Bergenholtz G, Spa ${ }^{\circ}$ ngberg L. Controversies in endodontics. Crit Rev Oral Biol Med. 2004; 15: 99-114.

[5] Spangberg LS. Evidence-based endodontics: the one-visit treatment idea. Oral Surg Oral Med Oral Pathol Oral Radiol Endod. 2001; 91: 617-618.

[6] Segura-Egea JJ, Cisneros-Cabello R, Llamas-Carreras JM, Velasco-Ortega E. Pain associated with root canal treatment. Int Endod J. 2009; 42: 614-620.

[7] Gondim E Jr, Setzer FC, Dos Carmo CB, Kim S. Postoperative pain after the application of two different irrigation devices in a prospective randomized clinical trial. J Endod. 2010; 36: 1295-1301.

[8] El Mubarak AH, Abu-bakr NH, Ibrahim YE. Postoperative pain in multiple-visit and single-visit root canal treatment. J Endod. 2010; 36: 36-9.

[9] Oliet S. Single visit endodontics: A clinical study. J Endod. 1983; 9: 147- 52.

[10] Ashkenaz PJ. One-visit endodontics: A preliminary report. Dent Surv. 1979; 55: 62-7.

[11] Risso PA, Cunha AJ, Araujo MC, Luiz RR. Post obturation pain and associated factors in adolescent patients undergoing one-and two visit root canal treatment. J Dent. 2008; 36: 928-34.

[12] Chapman HR, Kirby-Turner N. Visual/verbal analogue scales, examples of brief assessment methods to aid management of child and adult patients in clinical practice. Br Dent J. 2002; 193: 447-450.

[13] Price DD, McGrath PA, Rafi A, Bukingham B. The validation of visual analogue scales as ratio scale measures for chronic and experimental pain. Pain. 1983; 17: 45-46.

[14] DiRenzo A, Gresla T, Johnson BR, Rogers M, Tucker D, BeGole EA. Postoperative pain after 1-and 2-visit root canal therapy. Oral Surg Oral Med Oral Pathol. 2002; 93: 605-10.

[15] SuYingying, Wang chenglin, Ye ling. Healing Rate and Post-obturation Pain of Single- vs Multiple-visit Endodontic Treatment of Infected Root Canals. JOE. 2010.

[16] Ashkenaz PJ. One visit endodontics. Dent Clin North Am. 1984; 28(4): 853-63.

[17] Cohen S, Burns RC. One appointment root canal therapy; Case selection and treatment planning. Pathways of the Pulp, 6th Edition, Harcourt (India) Pvt. Limited, New Delhi. 1994: 70-72. 
[18] Kirchhoff AL, Fariniuk LF, Mello I. Apical extrusion of debris in flat-oval root canals after using different instrumentation systems. J Endod. 2015; 41: 237-41.

[19] Shetty H, Sontakke S, Karjodkar F, Gupta P,Mandwe A, Banga KS. A Cone Beam Computed Tomography (CBCT) evaluation of MB2 canals in endodontically treated permanent maxillary molars. A retrospective study in Indian population. J Clin Exp Dent. 2017; 9(1): e51-5.

[20] Walton RE, Holton IF Jr, Michelich R. Calcium Hydroxide as an Intracanal Medication: Effect on Post-treatment Pain. J Endod. 2003; 29(10): 627-9.

[21] Kvist T, Molander A, Dahlen G, Reit C. Microbiological evaluation of one- and two-visit endodontic treatment of teeth with apical periodontitis: a randomized, clinical trial. J Endod. 2004; 30: 572-6.

[22] Gupta R, Sharma H, Kumari R.A, Prakash A, Rai N, Jain L. Effectiveness of Two Techniques in Removal of Calcium Hydroxide Medicament from Root Canals: An in-vitro Assessment. Journal of Clinical and Diagnostic Research. 2018 Jul, 12(7): ZC53-ZC55.

[23] Moorer WR, Genet JM. Evidence for antibacterial activity of endodontic gutta-percha cones. Oral Surg Oral Med Oral Pathol. 1982; 53: 503-7.

[24] Eleazer PD, Eleazer KR. Flare-up rate in pulpally necrotic molars in one-visit versus two-visit endodontic treatment. J Endod. 1998; 24: 614-6.

[25] Fava LR. A comparison of one versus two appointment Endodontic therapy in teeth with non vital pulps. Int Endod J. 1989; 22: 179-83.

[26] Sun C, Sun J, Tan M, Hu B, Gao X, Song J. Pain after root canal treatment with different instruments: A systematic review and meta-analysis. Oral Dis. 2018 Sep; 24(6): 908-919.

[27] Jain A, Bahuguna R, Kashyap S, Ali A. Incidence of post endodontic pain after single visit root canal treatment with manual, rotary and rotary instruments with ultrasonic cleaning: a comparative study. Saudi J. Oral. Dent. Res. 2017; 2(4): 102-109.

[28] Çiçek E, Koçak MM, Koçak S, Sağlam BC, Türker SA. Postoperative pain intensity after using different instrumentation techniques: a randomized clinical study. J Appl Oral Sci. 2017 Jan-Feb; 25(1): 20-26.

[29] Alacam T. Incidence of postoperative pain following the use of different sealers in immediate root canal filling. J Endodo. 1985; 11: 135-7.

[30] Gupta S, Dhir S, Thakur BD, Talele KH, Bagwe AP, Gupta PP. Comparison of the Incidence of Post-operative Pain and Time Taken for Instrumentation Using Manual and Rotary Techniques and Obturation in Single-Visit Endodontics, in Young Permanent Teeth - An in Vivo Study.Int J Oral Care Res. 2018; 6(2): S15-18. 